TITLE:

\title{
Age-related changes in muscle thickness and echo intensity of trunk muscles in healthy women: comparison of 20-60s age groups
}

\section{$\operatorname{AUTHOR}(\mathrm{S}):$}

Ota, Megumi; Ikezoe, Tome; Kato, Takehiro;

Tateuchi, Hiroshige; Ichihashi, Noriaki

\section{CITATION:}

Ota, Megumi ...[et al]. Age-related changes in muscle thickness and echo intensity of trunk muscles in healthy women: comparison of 20-60s age groups. European journal of applied physiology 2020, 120: 1805-1814

ISSUE DATE:

2020-08

URL:

http://hdl.handle.net/2433/252812

\section{RIGHT:}

This is a post-peer-review, pre-copyedit version of an article published in European journal of applied physiology. The final authenticated version is available online at: $h$ ttp://dx.doi.org/10.1007/s00421-020-04412-7.; The full-text file will be made open to the public on 8 June 2021 in accordance with publisher's 'Terms and Conditions for Self-Archiving'.; この. 論文は出版社版でありません。引用の際には出版社版をご確認ご利用ください。; This is not the published version.

Please cite only the published version. 
Title

Age-related changes in muscle thickness and echo intensity of trunk muscles in healthy women: Comparison of 20s to 60s age groups

\section{Author names and affiliations}

Ota Megumi $^{\mathrm{a}}$, Ikezoe Tome ${ }^{\mathrm{b}}$, Kato Takehiro ${ }^{\mathrm{b}}$, Tateuchi Hiroshige ${ }^{\mathrm{a}}$, Ichihashi Noriaki ${ }^{\mathrm{b}}$

\section{Abbreviations}

EI; Echo intensity

MT; Muscle thickness

20s; 20-29 years old

30s; 30-39 years old

30s; 40-49 years old

50s; 50-59 years old

60s; 60-69 years old 


\begin{abstract}
Purpose: The objective of this study was to investigate the age-related changes in muscle thickness and muscle echo intensity of trunk in subjects including wide range of age groups. Methods: The subjects were 112 healthy women (age range, 20-60s). The rectus abdominis, external oblique, internal oblique, transversus abdominis, erector spinae, and lumbar multifidus muscles were examined. To confirm the differences among the age groups, the linear mixed effect models were performed. Results: There were significant decreases in muscle thickness of the rectus abdominis and external oblique muscles in the 50s and 60s age groups compared to those in the 20s age group, and a significant decrease in muscle thickness of the erector spinae muscle in the 60s age group compared to those in the 20s age group. However, there was no significant difference among the age groups in muscle thickness of other trunk muscles. There were significant increases in echo intensity of the abdominal muscles in other age groups compared to those in the 20s age group, and significant increases in echo intensity of the back muscles in the age groups over 40 compared to those in the 20s group. Conclusion: Our study revealed that muscle quality may be more affected by age than muscle quantity and the effects of aging differ among muscles.
\end{abstract}

Keywords: Aging, Ultrasonography, Muscle thickness, Echo intensity, Sarcopenia 


\section{Introduction}

It is well known that skeletal muscle mass decreases with advancing aging, and the age-related loss of muscle quantity has been labeled sarcopenia (Rosenberg, 1997; Cruz-Jentoft et al., 2010; Rosenberg, 2011). Previous studies using computed tomography (CT), magnetic resonance imaging (MRI), and dual-energy X-ray absorptiometry have provided substantial data on age-related loss of skeletal muscles (Rice et al., 1989; Kehayias et al., 1997; Gallagher et al., 1997, Gallagher and Heymsfield 1998; Janssen et al., 2000). Many recent studies measured the muscle thickness (MT) using ultrasonography as a more convenient and noninvasive method than CT or MRI as an indicator of muscle quantity (Janssen et al., 2000; Miyatani et al., 2003; Kubo et al., 2003; Candow and Chilibeck 2005; Arts et al., 2007, 2010; Ikezoe et al., 2011a, 2011b, 2012; Ota et al., 2012; Fukumoto et al., 2012a, 2015). It has been reported that MT has a high correlation with cadaveric dissection (Kellis et al., 2009; Cartwiright et al., 2013). The muscle cross-sectional area was measured using MRI (Dupont et al.; 2001; Miyatani et al., 2004), and the validity of MT measurements performed using ultrasonography have been verified.

Previous studies demonstrated that the lower limb muscles are more susceptible to aging than the upper limbs (Janssen et al., 2000; Miyatani et al., 2003; Kubo et al., 2003; Candow and Chilibeck 2005; Arts et al., 2007; Fukumoto et al., 2015). In addition, the degree of age-related changes in muscle quantity differs among the lower-limb muscles (Arts et al., 2010; Ikezoe et al., 2011a, 2011b; Fukumoto et al., 2015). Our previous studies (Ikezoe et al., 2011a, 2011b) revealed that MT values of the gluteus maximus, gluteus medius, gluteus minimus, psoas major, rectus femoris, vastus lateralis, vastus medialis, biceps femoris, and gastrocnemius muscles in older subjects were significantly thinner than those in young subjects, whereas no significant intergroup difference was seen in MT of the soleus.

Abdominal and back muscles play an important role in maintaining one’s upright position (Bogduk et al. 1992, Arjmand and Shirazi-Adl 2006) and they also contribute to gait (Marques et al. 2016). A previous study showed that compared to adults who were able to perform activities of daily living involving walking independently, greater atrophy of transversus abdominis and lumbar multifidus muscles was observed in older adults who were not able to maintain a sitting position independently (Ikezoe et al. 2012). Therefore, to maintain a physical activity level that acts against aging, it is important to retain abdominal and back muscle functions. It has been suggested that the degree of age-related changes in muscle quantity differs among trunk muscles as well (Ota et al., 2012; Ikezoe et al., 2012). Our previous study (Ota et al., 2012) investigating age-related changes in MT of abdominal muscles with five age groups (young, adult, middle-aged, young-old, and old-old) showed that the rectus abdominis muscle was significantly thicker in the young group than the other groups, and the external and internal oblique muscles were significantly thicker in the young group than in the middle-aged, young-old, and old-old groups. On the other hand, MT of the transversus abdominis muscle did not differ among the age groups. With regard to age-related changes in MT of abdominal muscles, the findings of our previous study (Ikezoe et al., 2012) indicated no significant difference in MT of the lumbar multifidus 
muscles between the independent older subjects and the young subjects, although the erector spinae muscles of the older subjects were thinner than those of the young subjects.

Furthermore, there are many recent previous studies on muscle echo intensity (EI) measured using a grayscale analysis of ultrasound images. When non-contractile tissues such as intramuscular fibrous and adipose tissues infiltrate between muscle fibers, the interface of the heterogeneous medium increases, and EI is enhanced (Pillen et al., 2009). It has been confirmed that EI correlates to the amount of intramuscular fibrous and adipose tissue, confirmed by muscle biopsies (Reimers et al., 1993, Pillen et al., 2009). In other words, an enhanced EI represents a decrease in the amount of contractile tissue, and it was concluded that EI is a practical and reproducible method that could be used as an imaging technique for the examination of intramuscular fat. Recent studies have shown that resistance training can elicit significant decreases in EI, which is considered an indication of non-contractile tissues in the muscles (Ikezoe et al.; 2017; Radaelli, et al.; 2014). Furthermore, muscle quality, which is quantified by EI, also changes with aging. With regard to the age-related changes in MT and EI of abdominal muscles, a previous study (Fukumoto et al., 2015) revealed that age-related changes in MT were observed in the rectus abdominis, external oblique, and internal oblique muscles, and not in the transversus abdominis muscle, while changes in EI were observed in all abdominal muscles. This study suggested that deep abdominal muscles such as the transversus abdominis muscle have less age-related muscle atrophy than superficial muscles like the rectus abdominis muscle do, and age-related changes in muscle quality of abdominal muscles may occur earlier than the muscle quantity loss that occurs over a life span. Thus, the age-related changes in MT and EI of abdominal muscles were investigated. However, no study has been performed that focuses on the age-related changes in EI of trunk muscles, including back muscles. Moreover, although previous studies on agerelated changes in EI targeted mainly older people, few studies have compared groups classified finely by age. Since the question of age group at which age-related changes occur remains unsettled in a comparative study of young and older subjects only, the appropriate stage of intervention time for preventing sarcopenia remains unclear. If age-related change in muscle quality occurs earlier than advanced age in abdominal and back muscles, all ages including pre middle-aged subjects should be targeted.

Here, this study aimed to investigate (a) the effect of age on MT or EI of abdominal and back muscles, and (b) whether there are age groups in which remarkable changes in MT or EI occur. We hypothesized that (a) age-related increases in the amount of non-contractile tissue such as intramuscular fat would be observed in not only abdominal and also back muscles, and that (b) the increases in the non-contractile tissue due to the promotion of heterotopic adipose differentiation may occur at an earlier age than muscle atrophy does.

\section{Material and methods}

\subsection{Participants}


Subjects comprised 112 healthy community-dwelling women (age range, 20-69 years; mean height, $158.0 \pm 4.4$ cm; mean mass, $52.9 \pm 7.3 \mathrm{~kg}$; mean body mass index, $21.2 \pm 2.5 \mathrm{~kg} / \mathrm{m}^{2}$ ). This study received approval from the ethics committee of Kyoto University Graduate School Faculty of Medicine. All subjects were given full written explanations before consenting to participate. The exclusion criterion was a current or past history of severe trauma or surgery and sustained pain. The inclusion criterion was independent daily living that included schoolwork, a job, or housework. Subjects were classified into five age groups: 20-29 years old (20s), 30-39 years old (30s), 40-49 years old (40s), 5059 years old (50s), and 60-69 years old (60s). The characteristics of each group are shown in Table 1. Height, mass, body mass indices, body fat percentages, and subcutaneous fat thickness on the rectus abdominis were compared among the age groups using the Tukey-Kramer method, and no significant intergroup differences were noted.

\subsection{Experimental protocol}

The subjects were examined in summer and winter. A Chi-squared test confirmed that values measured in the mornings and afternoons were not significantly different among the age groups. MT and EI were measured using Bmode ultrasonography devices (LOGIQ e; GE Healthcare UK Ltd., Chalfont, Buckinghamshiere, England) with multifrequency linear probes. Six trunk muscles were examined on the right side, including the rectus abdominis, external oblique, internal oblique, transversus abdominis, erector spinae, and lumbar multifidus muscles. The muscle measurement sites are illustrated in Fig. 1 (Ikezoe et al., 2012). The ultrasonography probe was applied vertically to the skin using the minimum pressure required to achieve a clear image, and cross-sectional images were taken. The subjects were asked to assume the supine position during abdominal muscle measurements and the prone position during abdominal muscle measurements. The subjects were instructed to breathe quietly in a resting supine position during abdominal muscle measurements. All probing techniques during measurements were performed by the same experienced investigator, and the images were taken at expiration by another experienced examiner. Our previous study showed that the test-retest reliability intraclass correlation coefficients (ICC) ranged from 0.87 to 0.99 for MT and EI measurements of lower limb and abdominal muscles, analyzed using two images taken on two separate days from the same healthy subjects (Fukumoto et al., 2012a, 2012b). Thus, the ultrasound measurements were confirmed to have a high reliability. Therefore, each measurement in this study was performed only once. The ultrasound settings including frequency $(8 \mathrm{MHz})$, gain $(58 \mathrm{~dB})$, and dynamic focus depth $(0 \mathrm{~cm})$ were kept consistent during the measurements.

\subsection{Measurement of MT}

MT was evaluated using an electric caliper on the ultrasound images as an index of muscle quantity. Each MT was determined as the distance between muscle tissue interfaces.

\subsection{Measurement of EI}

EI on ultrasound images was evaluated using computer-assisted 8-bit grayscale analysis by the standard histogram function in Image J (U. S. National Institutes of Health, Bethesda, MD, USA) as an index of muscle quality. 
A high EI represents the augmented proportion of intramuscular fat and interstitial fibrous tissue; thus, EI indicates muscle quality. A region of interest was selected in each muscle to include as much of the muscle as possible without any bone or surrounding fascia. The mean EI in the region of interest were calculated and expressed as a value of 0 (black) to 255 (white) (Fukumoto et al., 2012a, 2012b).

\subsection{Statistical analysis}

To investigate the age at which remarkable muscle atrophy and the increases in the non-contractile tissue occur, the differences in MT or EI among the age groups were examined by using the linear mixed effect models. These were performed with MT or EI of each muscle as dependent variables; subjects as random effects; and age groups, muscle parts, and confounding factors between age groups with muscle parts as fixed effects. The level of statistical significance was set at $5 \%$.

\section{Results}

Tables 2 and 3 summarize MT and EI results. The linear mixed effect models for MT were shown in Table 4, 5 and 6. There were significant differences in MT among age groups and muscle parts, and MTs of total trunk muscle in the 50s and 60s age groups were significantly smaller than those in the 20 s age group $(\mathrm{p}<0.01)$. Moreover, there were significant decreases compared to the 20s age group in MT of the rectus abdominis, external oblique, and erector spinae muscles. It was also revealed that MT values of the rectus abdominis and external oblique muscles were significantly smaller in the 50s and older groups than those in the 20s age group $(\mathrm{p}<0.05)$, and MT values of the erector spinae muscles were significantly smaller in the 60s age group than those in the 20 s age group $(\mathrm{p}<0.01)$. There was no significant difference in MT of the internal oblique, transversus abdominis, and lumbar multifidus muscles. The linear mixed effect models for EI were shown in Table 7, 8 and 9. There were significant differences in EI among age group and muscle part, and interaction of age group and muscle part was observed. EIs of total trunk muscles in other age groups were significantly larger than those in the 20s age group $(\mathrm{p}<0.01)$. Moreover, it has revealed that EI values of the abdominal muscles, including the internal oblique and transverse abdominis muscles, were significantly larger in all age groups compared to those in the 20s age group $(\mathrm{p}<0.01)$, and EI values of the back muscles, including the lumbar multifidus muscles, were significantly larger in the 40s and older groups than those in the 20s age group ( $\mathrm{p}<0.05$ ).

\section{Discussion}

The main findings of this study were that there were significant decreases compared to the 20s age group in MT of the rectus abdominis, external oblique, and erector spinae muscles only, whereas there were no significant differences among the age groups in MT of the internal oblique, transversus abdominis, and lumbar multifidus muscles. On the other hand, there were significant differences among the age groups in EI of all trunk muscles, and greater age- 
related changes in EI were seen than in MT in the younger groups. To our knowledge, this is the first report to show age-related changes including five age groups covering ages 20-69 years on MT and EI of the trunk muscles.

It is a well-known fact that muscle quantity and quantity decreases with aging. Our results revealed that the degree of age-related changes in muscle quantity and quantity differed among muscles; age-related changes of not only abdominal but also back muscles differed depending on each muscle. One reason for this is the differences in roles among muscles. Our previous study (Ikezoe et al., 2012) found that age-related muscle atrophy in the deep trunk muscles such as the transversus abdominis and lumbar multifidus muscles in older women who were able to independently perform activities of daily living were less than that in the superficial muscles such as the rectus abdominis and erector spinae muscles. On the other hand, MT of the transversus abdominis and the lumbar multifidus muscles in the older women who were impossible to independently maintain a seated position (i.e., chronically bedridden) were significantly thinner than those in young women and independent older women (Ikezoe et al., 2012), which suggests that the muscle quantity of the transversus abdominis and lumbar multifidus muscles among independent older adults may be maintained regardless of the aging process. The deep trunk muscles such as part of the internal oblique, transversus abdominis and lumbar multifidus muscles play an important role in stabilizing the lumbar spine (Bergmark, 1989). Since the subjects of this study were healthy community-dwelling women, muscle contractions during sitting and standing postures against gravity in daily physical activities may have contributed to maintaining muscle quantity of the transversus abdominis and lumbar multifidus muscles. Unlike our previous study (Ikezoe at al. 2012), this study indicated that that there were no differences among the age groups in MT of the internal oblique and erector spinae muscles, in addition to the deep trunk muscles. The subjects targeted were older in our previous study (old-old) (Ikezoe at al. 2012), whereas young-old or younger subjects were included in this study. In this context, another reason may be the composition of muscle fiber type, which is categorized into two main types: slow twitch (type I) and fast twitch (type II). The proportion of muscle fiber type differs depending on the muscle (Johnson et al. 1973; Sirca and Kostevc 1985; Rantanen et al. 1994; Lexell 1995). For example, the gastrocnemius and soleus muscles are the ankle flexor muscles, while the gastrocnemius muscle has a high proportion of type II fibers, whereas the soleus muscle has a high proportion of type I fibers (Johnson et al. 1973). Type II fibers are more affected by aging than are type I fibers. Age-related decreases in type II fiber diameters were observed, whereas there was no correlation between type I fiber diameter and age (Sato et al. 1984; Lexell et al. 1988; Nilwik et al. 2013; Kramer et al. 2017). The lumbar multifidus muscles have a high proportion of type I fibers (Sirca and Kostevc 1985; Rantanen et al. 1994), which may also influence the lower age-related atrophy in the lumbar multifidus muscles among healthy independent subjects.

Even though there was no significant difference in MT of the internal oblique, transversus abdominis, and lumbar multifidus muscles, EI of all trunk muscles were significantly different among the age groups. The reason for 
this is that MT seems to be influenced by non-contractile tissue in addition to the muscle fibers. Even if the muscle areas of the vastus lateralis muscle of the older and young subjects were same, the total fiber area of the late older subjects was smaller than that of the young subjects (Lexell et al. 1988). Moreover, in studies targeting paraspinal muscles, although it is noted that cross-sectional area of the paraspinal muscles was not correlated with age, paraspinal fat fractions correlated directly with age (Dahlqvist et al. 2017). The effects of aging may increase the non-contractile tissue such as intramuscular fat and interstitial fibrous tissue and reduce the amount of substantial muscle fibers. With regard to the physiological mechanism of the age-related changes in MT and EI, sarcopenia, unlike muscle atrophy due to disuse, involves not only muscle fiber atrophy but also a decrease in the number of muscle fibers. It is considered that one of the reasons for this is that the number and proliferation function of muscle satellite cells involved in muscle regeneration decrease with age (Hawke and Garry 1985; Machida and Booth 2004). Furthermore, since muscle cells produced from the muscle satellite cells function in suppressing heterotopic adipose differentiation, muscle atrophy promotes heterotopic adipose differentiation (Uzumi et al. 2010). Promoting heterotopic adipose differentiation due to decreases in proliferation function of muscle satellite cells may occur at an earlier age than muscle fiber atrophy and a decrease in the number of muscle fibers. Therefore, this study potentially found that EI as an index of the proportion of non-contractile tissue such as intramuscular fat may be more susceptible to aging than MT as an index of muscle atrophy. The results of the linear mixed effect models, it was revealed that MTs of total trunk muscles in the age groups over 50 were significantly smaller than those in the 20s age group, and EIs of total trunk muscles in the age groups over 30 were significantly larger than those in the 20s age group. In other words, although age-related decreases in muscle quantity occur after 50 years of age, age-related changes in muscle quality occur after 30 years of age. Although the previous study (Fukumoto et al., 2015) also revealed that age-related changes in muscle quality may occur earlier than age-related changes in muscle quantity, but the previous study did not include subjects 30-40 years of age. Our results showed that age-related changes in abdominal muscle quality occur before middle age. Since muscle strength would be affected by muscle quantity and quality (Fukumoto et al., 2012a; Watanabe et al., 2013; Taniguchi et al., 2017), agerelated decreases in muscle strength at an earlier age may be more affected by muscle quality than quantity. Therefore, to prevent age-related muscle weakness, it is appropriate to evaluate MT at EI in subjects over 30 years old. Another feature of this study is that we examined not only abdominal muscles but also abdominal muscles. Similar to the results of previous studies examining lower limbs and abdomen muscles, it was found that age-related changes in back muscles are differ depending on each muscle.

Several limitations to this study should be noted. Because this was a cross-sectional study using the linear mixed effect models, the causes for these changes are not clear, and it is not known whether our results are applicable to longitudinal changes in individual subjects. Another limitation of this study is our inclusion of only women. Reports showed sex-related differences in the degrees of age-related changes in muscle quantity (Janssen et al., 2000). Further 
longitudinal studies including both men and women would be required to confirm age-related change in muscle quantity and quality. The other limitation is that muscle strength was not measured in this study. Therefore, although MT and EI are related to muscle strength (Fukumoto et al., 2012a; Watanabe et al., 2013; Taniguchi et al., 2017), the influence of changes in MT and EI on performance such as muscle strength remains unknown. Finally, body composition has been reported to be affected by various factors; food and water intake, fitness level, water concentration, physical activity, menstruation, and circadian variations (Chumlea et al., 1996; Deurenberg et al., 1988; Shiose et al., 2017). To generalize our findings, studies that consider these factors are required.

\section{Conclusion}

We found significant decreases in MT of the rectus abdominis and external oblique muscles in the 50s and 60s age groups compared to those in the 20s age group, and MT of the erector spinae muscle in the 60s age groups compared to those in the 20s age group. There was no significant difference among the age groups in muscle thickness of the internal oblique, transversus abdominis, and lumbar multifidus muscles. Our study indicated that age-related changes in MT were smaller in the deep trunk muscles such as the internal oblique, transversus abdominis, and lumbar multifidus muscles. On the other hand, there were significant differences in EI of all abdominal muscles between the 20s age group and other age groups, and significant differences in EI of all back muscles in the age groups over 40 compared to those in the 20s age group. Our study revealed that muscle quality may be more affected by age than muscle quantity, while age-related changes in muscle quality may occur even in the 30s age group.

\section{Acknowledgements}

We thank all of our study subjects for their participation.

\section{Funding}

\section{Conflicts}

The authors declare financial conflicts of interest concerning this study. This study was supported by a joint research fund from Wacoal Holdings Corporation. 


\section{References}

Arjmand N, Shirazi-Adl A (2006) Role of intra-abdominal pressure in the unloading and stabilization of the human spine during static lifting tasks. Eur Spine J 15:1265-1275. doi: 10.1007/s00586-005-0012-9

Arts IM, Pillen S, Overeem S, Schelhaas HJ, Zwarts MJ (2007) Rise and fall of skeletal muscle size over the entire life span. J Am Geriatr Soc 55:1150-1152. doi: 10.1111/j.1532-5415.2007.01228.x

Arts IM, Pillen S, Schelhaas HJ, Overeem S, Zwarts MJ (2010) Normal values for quantitative muscle ultrasonography in adults. Muscle Nerve 41:32-41. doi: 10.1002/mus.21458

Bergmark A (1989) Stability of the lumbar spine. A study in mechanical engineering. Acta Orthop Scand 230:1-54.

Bogduk N, Macintosh JE, Pearcy MJ A universal model of the lumbar back muscles in the upright position. Spine 1992; 17:897-913. doi: 10.3109/17453678909154177

Candow DG, Chilibeck PD (2005) Differences in Size, Strength, and Power of Upper and Lower Body Muscle Groups in Young and Older Men. J Gerontol A Biol Sci Med Sci 60:148-156. doi: 10.1093/gerona/60.2.148

Cartwright, M.S., Demar, S., Griffin, L.P., Balakrishnan, N., Harris, J.M., Walker, F.O. (2013) Validity and reliability of nerve and muscle ultrasound. Muscle \& Nerve, 47, 515-521. doi: 10.1002/mus.23621

Chumlea, W.C., Guo, S.S., Cockram, D.B., Siervogel, S.S. (1996) Mechanical and physiologic modifiers and bioelectrical impedance spectrum determinants of body composition. American Journal of Clinical Nutrition, 64, 413422. doi: 10.1093/ajcn/64.3.413S

Cruz-Jentoft AJ, Baeyens JP, Bauer JM, Boirie Y, Cederholm T, Landi F, Martin FC, Michel JP, Rolland Y, Schneider SM, Topinkova E, Vandewoude M, Zamboni M (2010) Sarcopenia: European Working Group on Sarcopenia in Older People. Sarcopenia: European consensus on definition and diagnosis: Report of the European Working Group on Sarcopenia in Older People. Age Ageing 39;412-423. doi: 10.1093/ageing/afq034

Dahlqvist JR, Vissing CR, Hedermann G, Thomsen C, Vissing J (2017) Fat Replacement of Paraspinal Muscles with Aging in Healthy Adults. Med Sci Sports Exerc 49:595-601. doi: 10.1249/MSS.0000000000001119

Deurenberg, P., Weststrate, J.A., Paymans, I., van der Kooy, K. (1988) Factors affecting bioelectrical impedance measurements in humans. European Journal of Clinical Nutrition, 42, 1017-1022.

Dupont, A.C., Sauerbrei, E.E., Fenton, P.V., Shragge, P.C., Loeb, G.E., Richmond, F.J. (2001) Real-time sonography to estimate muscle thickness: comparison with MRI and CT. Journal of Clinical Ultrasound 29, 230-2360 doi:

10.1002/jcu.1025

Evans, J.D. (1996) Straightforward statistics for the behavioral sciences. Pacific Grove: Brooks/Cole Pub. Co., Stamford

Fukumoto Y, Ikezoe T, Yamada Y, Tsukagoshi R, Nakamura M, Mori N, Kimura M, Ichihashi N (2012a) Skeletal muscle quality assessed from echo intensity is associated with muscle strength of middle-aged and elderly persons. Eur 
J Appl Physiol 112:1519-1525. doi: 10.1007/s00421-011-2099-5

Fukumoto, Y., Ikezoe, T., Tateuchi, H., Tsukagoshi, R., Akitama, H., So, K., Kuroda, Y., Yoneyama, T., Ichihashi, N. (2012b) Muscle Mass and Composition of the Hip, Thigh and Abdominal Muscles in Women With and Without Hip Osteoarthritis. Ultrasound in Medicine and Biology, 38, 1540-1545. doi: 10.1016/j.ultrasmedbio.2012.04.016

Fukumoto Y, Ikezoe T, Yamada Y, Tsukagoshi R, Nakamura M, Takagi Y, Kimura M, Ichihashi N (2015) Age-Related Ultrasound Changes in Muscle Quantity and Quality in Women. Ultrasound Med Biol 41:3013-3017. doi:

10.1016/j.ultrasmedbio.2015.06.017

Gallagher D, Visser M, De Meersman RE, Sepu' lveda D, Baumgartner RN, Pierson RN, Harris T, Heymsfield SB (1997) Appendicular skeletal muscle mass: effects of age, gender, and ethnicity. J Appl Physiol 83:229-239.

Gallagher D, Heymsfield SB (1998) Muscle distribution: variations with body weight, gender, and age. Appl Radiat Isot 49:733-734. doi: 10.1152/jappl.1997.83.1.229

Hawke, T.J., Garry, D.J. (1985) Myogenic satellite cells: physiology to molecular biology. Journal of Applied Physiology, 91, 534-551. doi: 10.1152/jappl.2001.91.2.534

Ikezoe T, Mori N, Nakamura M, Ichihashi N (2011a) Age-related muscle atrophy in the lower extremities and daily physical activity in elderly women. Arch Gerontol Geriatr 53:e153-157. doi: 10.1016/j.archger.2010.08.003 Ikezoe T, Mori N, Nakamura M, Ichihashi N (2011b) Atrophy of the lower limbs in elderly women: is it related to walking ability? Eur J Appl Physiol 111:989-995. doi: 10.1007/s00421-010-1728-8

Ikezoe T, Mori N, Nakamura M, Ichihashi N (2012) Effects of age and inactivity due to prolonged bed rest on atrophy of trunk muscles. Eur J Appl Physiol 112:43-48. doi: 10.1007/s00421-011-1952-X

Ikezoe, T., Kobayashi, T., Nakamura, M., Ichihashi, N. (2017) Effects of low-load, higher-repetition versus high-load, lower-repetition resistance training not performed to failure on muscle strength, mass, and echo intensity in healthy young men: a time-course study. Journal of Strength and Conditioning Research. doi: 10.1519/JSC.0000000000002278 Janssen I, Heymsfield SB, Wang Z, Ross R (2000) Skeletal muscle mass and distribution in 468 men and women aged 18-88 yr. J Appl Physiol 89:81-88. doi: 10.1152/japplphysiol.zdg-1052-corr.2014

Johnson. MA, Polgar J, Weightman D, Appleton D (1973) Data on the distribution of fibre types in thirty-six human muscles. J Neurol Sci 18:111-129. doi: 10.1016/0022-510x(73)90023-3

Kehayias JJ, Fiatarone MA, Zhuang H, Roubenoff R (1997) Total body potassium and body fat: relevance to aging. Am J Clin Nutr 66:904-910. doi: 10.1093/ajcn/66.4.904

Kellis, E., Galanis, N., Natsis, K., Kapetanos, G. (2009) Validity of architectural properties of the hamstring muscles: correlation of ultrasound findings with cadaveric dissection. Journal of Biomechanics, 42, 2549-2554. doi:

10.1016/j.jbiomech.2009.07.011

Kramer IF, Snijders T, Smeets JSJ, Leenders M, van Kranenburg J, den Hoed M, Verdijk LB, Poeze M, van Loon LJC 
(2017) Extensive Type II Muscle Fiber Atrophy in Elderly Female Hip Fracture Patients. J Gerontol A Biol Sci Med Sci 72:1369-1375. doi: 10.1093/gerona/glw253

Kubo K, Kanehisa H, Azuma K, Ihizu M, Kuno S, Okada M, Fukunaga T (2003) Muscle architectural characteristics in women aged 20-79 years. Med Sc. Sports Exerc 35:39-44. doi: 10.1249/01.MSS.0000043385.66520.09

Lexell J, Taylor CC, Sjöström M (1988) What is the cause of the ageing atrophy? Total number, size and proportion of different fiber types studied in whole vastus lateralis muscle from 15- to 83-year-old men. J Neurol Sci 84:275-294. doi: 10.1016/0022-510X(88)90132-3

Lexell J (1995) Human aging, muscle mass, and fiber type composition. J Gerontol A Biol Sci Med Sci. 50:11-16. doi: 10.1093/gerona/50A.Special_Issue.11

Machida, S., Booth, F.W. (2004) Increased nuclear proteins in muscle satellite cells in aged animals as compared to young growing animals. Experimental Gerontology, 39, 1521-1425. doi: 10.1016/j.exger.2004.08.009 Marques NR, Hallal CZ, Spinoso DH, Crozara LF, Morcelli MH, Karuka AH, Navega M, Gonçalves M (2016) Agerelated alterations in the activation of trunk and lower limb muscles during walking. J Back Musculoskelet Rehabil 29:295-300. doi: 10.3233/BMR-150628

Miyatani M, Kanehisa H, Azuma K, Kuno S, Fukunaga T (2003) Site-related differences in muscles loss with aging “A cross-sectional survey on the muscle thickness in Japanese men aged 20 to 79 years”. Int J Sport Health Sci 1:34-40. doi: 10.5432/ijshs.1.34

Miyatani, M., Kanehisa, H., Ito, M., Kawakami, Y., Fukunaga, T. (2004) The accuracy of volume estimates using ultrasound muscle thickness measurements in different muscle groups. European Journal of Applied Physiology, 91, 264-272. doi: 10.1007/s00421-003-0974-4

Nilwik R, Snijders T, Leenders M, Groen BB, van Kranenburg J, Verdijk LB, van Loon. LJ (2013) The decline in skeletal muscle mass with aging is mainly attributed to a reduction in type II muscle fiber size. Exp Gerontol 48:492498. doi: 10.1016/j.exger.2013.02.012

Ota M. Ikezoe T, Kaneoka K, Ichihashi N (2012) Age-related changes in the thickness of the deep and superficial abdominal muscles in women. Arch Gerontol Geriatr 55:e26-30. doi: 10.1016/j.archger.2012.03.007

Pillen S, Tak RO, Zwarts MJ, Lammens MM, Verrijp KN, Arts IM, van der Laak JA, Hoogerbrugge PM, van Engelen BG, Verrips A (2009) Skeletal muscle ultrasound: correlation between fibrous tissue and echo intensity. Ultrasound Med Biol 35:443-446. doi: 10.1016/j.ultrasmedbio.2008.09.016

Radaelli, R., Botton, C.E., Wilhelm, E.N., Bottaro, M., Brown, L.E., Lacerda, F., Gaya, A., Moraes, K., Peruzzolo, A., Pinto, R.S. (2014) Time course of low- and high-volume strength training on neuromuscular adaptations and muscle quality in older women. Age (Dordrecht, Netherlands: Online), 36, 881-92. doi: 10.1007/s11357-013-9611-2

Rantanen J, Rissanen A, Kalimo H (1994) Lumbar muscle fiber size and type distribution in normal subjects. Eur Spine 
J 3:331-335. doi: 10.1007/bf02200146

Reimers, K., Reimers, C.D., Wagner, S., Paetzke, I., Pongratz, D.E. (1993) Skeletal muscle sonography: a correlative study of echogenicity and morphology. Journal of Ultrasound in Medicine, 12, 73-77. doi: 10.7863/jum.1993.12.2.73 Rice CL, Cunningham DA, Paterson DH., Lefcoe MS (1989) Arm and leg composition determined by computed tomography in young and elderly men. Clin Physiol 9:207-220. doi: 10.1111/j.1475-097x.1989.tb00973.x

Rosenberg IH (1997) Sarcopenia: origins and clinical relevance. J Nutr 127: 990S-991S. doi: 10.1093/jn/127.5.990S

Rosenberg IH (2011) Sarcopenia: origins and clinical relevance. Clin Geriatr Med 27:337-339. doi:

10.1016/j.cger.2011.03.003

Sato T, Akatsuka H, Kito K, Tokoro Y, Tauchi H, Kato K (1984) Age changes in size and number of muscle fibers in human minor pectoral muscle. Mech Ageing Dev 28:99-109. doi: 10.1016/0047-6374(84)90156-8

Sirca A, KostevcV (1985) The fibre type composition of thoracic and lumbar paravertebral muscles in man. J Anat $141,131-137$.

Taniguchi M, Yamada Y, Fukumoto Y, Sawano S, Minami S, Ikezoe T, Watanabe Y, Kimura M, Ichihashi N (2017) Increase in echo intensity and extracellular-to-intracellular water ratio is independently associated with muscle weakness in elderly women. Eur J Appl Physiol 117:2001-2007. doi: 10.1007/s00421-017-3686-X

Uezumi, A., Fukada, S., Yamamoto, N., Takeda, S., Tsuchida, K. (2010) Mesenchymal progenitors distinct from satellite cells contribute to ectopic fat cell formation in skeletal muscle. Nature Cell Biology, 12, 143-152. doi: $10.1038 /$ ncb2014

Watanabe Y, Yamada Y, Fukumoto Y, Ishihara T, Yokoyama K, Yoshida K, Miyake M, Yamagata E, Kimura M (2013) Echo intensity obtained from ultrasonography images reflecting muscle strength in elderly men. Clin Interv Aging 8:993-998. doi: 10.2147/CIA.S47263

Young HJ, Jenkins NT, Zhao Q, Mccully KK (2015) Measurement of intramuscular fat by muscle echo intensity. Muscle Nerve 52:963-971. doi: 10.1002/mus.24656 


\section{Figure captions}

Fig. 1. Measurement site for each muscle: (a) Rectus abdominis, $3 \mathrm{~cm}$ lateral to the umbilicus; (b) External oblique, internal oblique, and transversus abdominis, $2.5 \mathrm{~cm}$ anterior to the midaxillary line at the midpoint between the inferior rib and the iliac crest; (c) Erector spinae, $4 \mathrm{~cm}$ lateral to the Th9 spinous process; and (d) Lumbar multifidus, $2 \mathrm{~cm}$ lateral to the L4 spinous process.

These images were provided by Visible Body and modified for our purposes. 

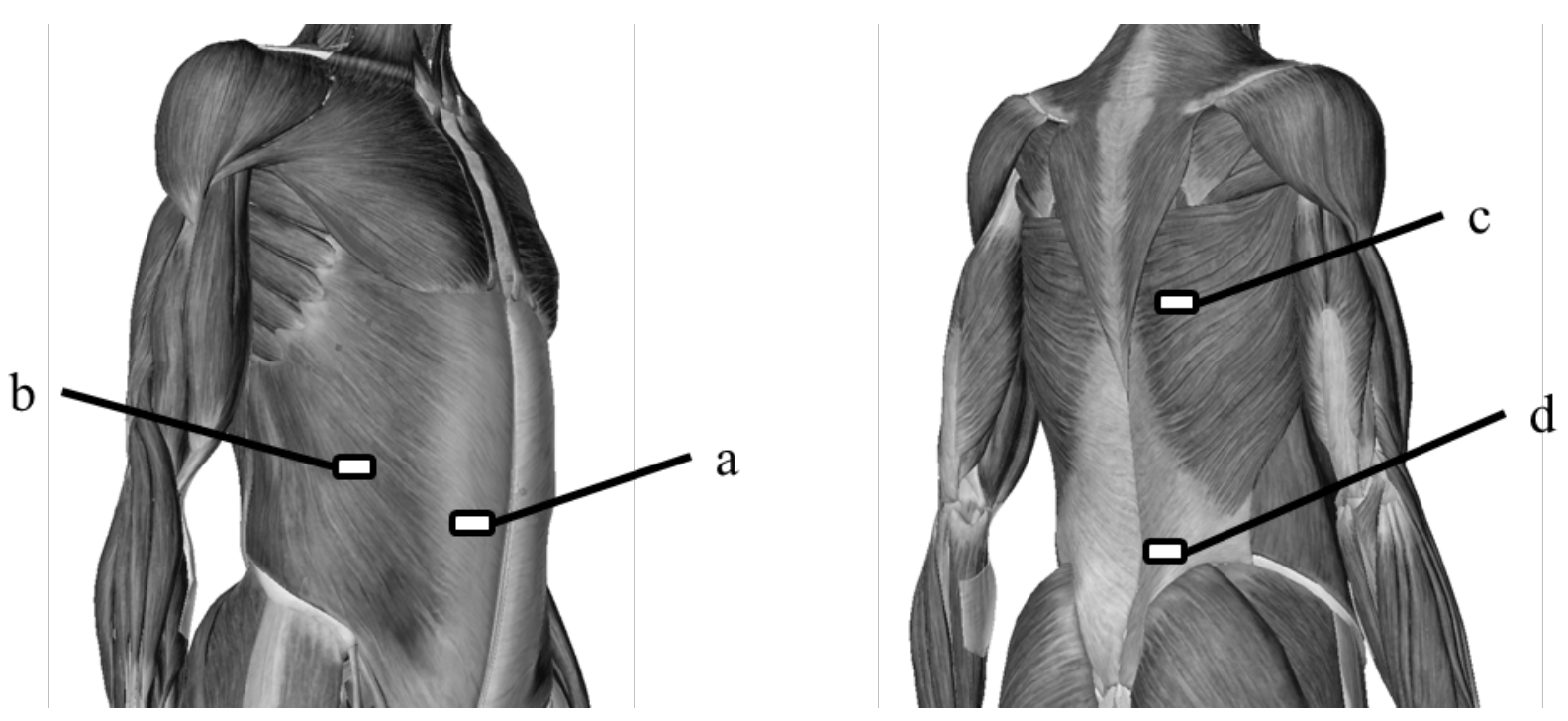
Table 1. Characteristics of each group

\begin{tabular}{|c|c|c|c|c|c|c|c|}
\hline Age group & Number & $\begin{array}{r}\text { Age } \\
\text { (years old) }\end{array}$ & $\begin{array}{r}\text { Height } \\
\text { (cm) }\end{array}$ & $\begin{array}{r}\text { Mass } \\
(\mathrm{kg})\end{array}$ & $\begin{array}{r}\text { BMI } \\
\left(\mathrm{kg} / \mathrm{m}^{2}\right)\end{array}$ & $\begin{array}{r}\text { Body fat percentage } \\
\text { (\%) }\end{array}$ & $\begin{array}{l}\text { Subcutaneous fat thickness on the rectus abdominis } \\
\text { (mm) }\end{array}$ \\
\hline $20 \mathrm{~s}$ & 23 & $24.04 \pm 2.64$ & $158.31 \pm 5.19$ & $53.77 \pm 7.88$ & $21.41 \pm 2.61$ & $28.47 \pm 5.94$ & $15.93 \pm 7.33$ \\
\hline $30 \mathrm{~s}$ & 18 & $33.94 \pm 2.58$ & $157.67 \pm 4.76$ & $52.23 \pm 7.10$ & $20.99 \pm 2.59$ & $26.48 \pm 4.60$ & $12.52 \pm 4.59$ \\
\hline $40 \mathrm{~s}$ & 22 & $45.09 \pm 2.60$ & $159.51 \pm 4.16$ & $55.47 \pm 7.86$ & $21.78 \pm 2.81$ & $27.14 \pm 7.48$ & $12.98 \pm 7.83$ \\
\hline $50 \mathrm{~s}$ & 26 & $54.00 \pm 2.55$ & $157.77 \pm 3.52$ & $51.69 \pm 6.84$ & $20.73 \pm 2.30$ & $26.19 \pm 6.27$ & $12.70 \pm 6.28$ \\
\hline $60 \mathrm{~s}$ & 23 & $63.74 \pm 2.90$ & $156.53 \pm 4.46$ & $51.51 \pm 6.37$ & $20.98 \pm 2.00$ & $26.80 \pm 5.10$ & $12.93 \pm 6.08$ \\
\hline
\end{tabular}

Abbreviations: BMI, body mass index

Foot note:

Data are expressed as mean \pm standard deviation. 
Table 2. Data are expressed as mean \pm standard deviation of muscle thickness $(\mathrm{mm})$ among the age groups

\begin{tabular}{|c|c|c|c|c|c|}
\hline Muscle & $20 \mathrm{~s} \quad(\mathrm{n}=23)$ & $30 \mathrm{~s}(\mathrm{n}=18)$ & $40 \mathrm{~s}(\mathrm{n}=22)$ & $50 \mathrm{~s}(\mathrm{n}=26)$ & $60 \mathrm{~s}(\mathrm{n}=23)$ \\
\hline Rectus abdominis & $9.59 \pm 1.75$ & $8.94 \pm 1.86$ & $8.20 \pm 1.85$ & $7.72 \pm 2.13$ & $7.27 \pm 1.39$ \\
\hline External oblique & $6.15 \pm 1.45$ & $5.77 \pm 1.49$ & $5.31 \pm 1.40$ & $4.39 \pm 1.16$ & $4.35 \pm 1.11$ \\
\hline Internal oblique & $7.02 \pm 1.72$ & $6.72 \pm 1.88$ & $6.57 \pm 1.60$ & $6.08 \pm 1.70$ & $6.05 \pm 1.81$ \\
\hline Transversus abdominis & $3.72 \pm 0.49$ & $3.92 \pm 1.18$ & $3.78 \pm 1.13$ & $3.28 \pm 0.65$ & $3.58 \pm 0.82$ \\
\hline Erector spinae & $19.86 \pm 2.63$ & $18.65 \pm 3.01$ & $18.85 \pm 3.74$ & $18.60 \pm 2.88$ & $17.45 \pm 4.09$ \\
\hline Lumbar multifidus & $26.25 \pm 3.76$ & $27.18 \pm 4.45$ & $26.65 \pm 4.53$ & $27.87 \pm 4.66$ & $26.85 \pm 4.27$ \\
\hline
\end{tabular}


Table 3. Data are expressed as mean \pm standard deviation of echo intensity (0-255) among the age groups

\begin{tabular}{lccccc}
\hline Muscle & 20s $(\mathrm{n}=23)$ & $30 \mathrm{~s}(\mathrm{n}=18)$ & $40 \mathrm{~s}(\mathrm{n}=22)$ & $50 \mathrm{~s}(\mathrm{n}=26)$ & $60 \mathrm{~s}(\mathrm{n}=23)$ \\
\hline Rectus abdominis & $38.93 \pm 28.58$ & $60.52 \pm 18.68$ & $73.13 \pm 18.35$ & $82.24 \pm 14.34$ & $87.61 \pm 20.98$ \\
External oblique & $56.77 \pm 17.17$ & $73.50 \pm 10.82$ & $81.74 \pm 13.39$ & $85.18 \pm 10.56$ & $88.23 \pm 13.49$ \\
Internal oblique & $31.37 \pm 19.43$ & $45.42 \pm 10.48$ & $52.49 \pm 13.91$ & $66.17 \pm 11.95$ & $64.30 \pm 17.64$ \\
Transversus abdominis & $19.42 \pm 13.36$ & $32.90 \pm 12.84$ & $34.07 \pm 15.69$ & $48.68 \pm 13.12$ & $46.00 \pm 17.61$ \\
Erector spinae & $36.14 \pm 16.71$ & $41.89 \pm 12.50$ & $47.91 \pm 14.87$ & $54.54 \pm 12.72$ & $64.11 \pm 15.87$ \\
Lumbar multifidus & $30.22 \pm 13.21$ & $34.23 \pm 14.02$ & $41.06 \pm 14.91$ & $49.52 \pm 10.08$ & $51.36 \pm 12.90$ \\
\hline
\end{tabular}


Table 4. Fixed effect in the linear mixed effect models for MT

\begin{tabular}{rr}
\hline & p value \\
\hline Intercept & $<\mathbf{0 . 0 1}$ \\
Age group & $<\mathbf{0 . 0 1}$ \\
Muscle part & $<\mathbf{0 . 0 1}$ \\
Age group $\times$ Muscle part & 0.272 \\
\hline
\end{tabular}

Table 5. The linear mixed effect models for MT of total muscles among the age groups.

\begin{tabular}{|c|c|c|c|c|}
\hline Age group & Least squares mean & $95 \%$ & Confidence interval & $\mathrm{p}$ value \\
\hline $20 s$ & 12.10 & & $11.67-12.52$ & \\
\hline $30 s$ & 11.86 & & $11.38-12.34$ & 0.470 \\
\hline $40 s$ & 11.56 & & $11.13-11.99$ & 0.082 \\
\hline $50 \mathrm{~s}$ & 11.32 & & $10.92-11.72$ & $<0.01$ \\
\hline $60 s$ & 10.92 & & $10.50-11.35$ & $<0.01$ \\
\hline
\end{tabular}


Table 6. The linear mixed effect models for MT of each muscle among the age groups.

\begin{tabular}{|c|c|c|c|c|}
\hline Muscle & Age group & Least squares mean & 95\% Confidence interval & $\mathrm{p}$ value \\
\hline \multirow{5}{*}{ Rectus abdominis } & $20 \mathrm{~s}$ & 9.59 & $8.55-10.63$ & \\
\hline & $30 s$ & 8.94 & $7.77-10.12$ & 0.419 \\
\hline & $40 s$ & 8.20 & $7.14-9.26$ & 0.067 \\
\hline & $50 s$ & 7.72 & $6.74-8.69$ & $<0.01$ \\
\hline & $60 s$ & 7.27 & $6.23-8.30$ & $<0.01$ \\
\hline \multirow{5}{*}{ External oblique } & $20 s$ & 6.15 & $5.11-7.19$ & \\
\hline & $30 s$ & 5.77 & $4.59-6.94$ & 0.630 \\
\hline & $40 \mathrm{~s}$ & 5.31 & $4.25-6.37$ & 0266 \\
\hline & $50 \mathrm{~s}$ & 4.39 & $3.41-5.37$ & $<0.05$ \\
\hline & $60 s$ & 4.35 & $3.31-5.39$ & $<0.05$ \\
\hline \multirow{5}{*}{ Internal oblique } & $20 \mathrm{~s}$ & 7.02 & $5.98-8.06$ & \\
\hline & $30 s$ & 6.72 & $5.54-7.89$ & 0.703 \\
\hline & $40 \mathrm{~s}$ & 6.57 & $5.51-7.64$ & 0.553 \\
\hline & $50 \mathrm{~s}$ & 6.08 & $5.11-7.06$ & 0.198 \\
\hline & $60 \mathrm{~s}$ & 6.05 & $5.01-7.09$ & 0.194 \\
\hline \multirow{5}{*}{ Transversus abdominis } & $20 s$ & 3.72 & $2.68-4.76$ & \\
\hline & $30 s$ & 3.92 & $2.74-5.09$ & 0.803 \\
\hline & $40 \mathrm{~s}$ & 3.78 & $2.71-4.84$ & 0.937 \\
\hline & $50 \mathrm{~s}$ & 3.28 & $2.31-4.26$ & 0.552 \\
\hline & $60 \mathrm{~s}$ & 3.58 & $2.54-4.62$ & 0.853 \\
\hline \multirow{5}{*}{ Erector spinae } & $20 \mathrm{~s}$ & 19.86 & $18.82-20.90$ & \\
\hline & $30 \mathrm{~s}$ & 18.65 & $17.47-19.83$ & 0.132 \\
\hline & $40 \mathrm{~s}$ & 18.85 & $17.79-19.91$ & 0.184 \\
\hline & $50 \mathrm{~s}$ & 18.60 & $17.62-19.57$ & 0.083 \\
\hline & $60 \mathrm{~s}$ & 17.45 & $16.41-18.49$ & $<0.01$ \\
\hline \multirow{5}{*}{ Lumbar multifidus } & $20 \mathrm{~s}$ & 26.25 & $25.21-27.29$ & \\
\hline & $30 s$ & 27.18 & $26.00-28.35$ & 0.245 \\
\hline & $40 \mathrm{~s}$ & 26.65 & $25.59-27.71$ & 0.596 \\
\hline & $50 \mathrm{~s}$ & 27.87 & $26.89-28.85$ & $<0.05$ \\
\hline & $60 s$ & 26.85 & $25.81-27.89$ & 0.420 \\
\hline
\end{tabular}

Foot note: the linear mixed effect models were performed by MT or EI of each muscle as dependent variables; subjects as random effects; and age groups, muscle parts, and confounding factors between age groups with muscle parts as fixed effects. Significant difference compared to the 20s age group are shown in bold. 
Table 7. Fixed effect in the linear mixed effect models for EI

\begin{tabular}{rr}
\hline & p value \\
\hline Intercept & $<\mathbf{0 . 0 1}$ \\
Age group & $<\mathbf{0 . 0 1}$ \\
Muscle part & $<\mathbf{0 . 0 1}$ \\
Age group $\times$ Muscle part & $<\mathbf{0 . 0 1}$ \\
\hline
\end{tabular}

Table 8. The linear mixed effect models for EI of total muscles among the age groups.

\begin{tabular}{|c|c|c|c|c|}
\hline Age group & Least squares mean & $95 \%$ & Confidence interval & $\mathrm{p}$ value \\
\hline $20 \mathrm{~s}$ & 35.48 & & $32.89-38.06$ & \\
\hline $30 s$ & 48.08 & & $45.15-51.00$ & $<\mathbf{0 . 0 1}$ \\
\hline $40 \mathrm{~s}$ & 55.07 & & $52.42-57.71$ & $<0.01$ \\
\hline $50 \mathrm{~s}$ & 64.39 & & $61.96-66.82$ & $<0.01$ \\
\hline $60 \mathrm{~s}$ & 66.93 & & $64.35-69.52$ & $<0.01$ \\
\hline
\end{tabular}


Table 9. The linear mixed effect models for EI of each muscle among the age groups.

\begin{tabular}{|c|c|c|c|c|}
\hline Muscle & Age group & Least squares mean & 95\% Confidence interval & $\mathrm{p}$ value \\
\hline \multirow{5}{*}{ Rectus abdominis } & $20 \mathrm{~s}$ & 38.93 & $32.60-45.27$ & \\
\hline & $30 s$ & 60.52 & $53.36-67.68$ & $<0.01$ \\
\hline & $40 s$ & 73.13 & $66.66-79.61$ & $<0.01$ \\
\hline & $50 s$ & 82.24 & $76.29-88.20$ & $<\mathbf{0 . 0 1}$ \\
\hline & $60 s$ & 87.61 & $81.27-93.94$ & $<0.01$ \\
\hline \multirow{5}{*}{ External oblique } & $20 s$ & 56.77 & $50.44-63.10$ & \\
\hline & $30 s$ & 73.50 & $66.34-80.66$ & $<0.01$ \\
\hline & $40 \mathrm{~s}$ & 81.74 & $75.26-88.21$ & $<0.01$ \\
\hline & $50 \mathrm{~s}$ & 85.18 & $79.23-91.14$ & $<0.01$ \\
\hline & $60 s$ & 88.23 & $81.90-94.56$ & $<0.01$ \\
\hline \multirow{5}{*}{ Internal oblique } & $20 \mathrm{~s}$ & 31.37 & $25.04-37.70$ & \\
\hline & $30 s$ & 45.42 & $38.26-52.58$ & $<0.01$ \\
\hline & $40 \mathrm{~s}$ & 52.49 & $46.01-58.96$ & $<0.01$ \\
\hline & $50 \mathrm{~s}$ & 66.17 & $60.22-72.13$ & $<0.01$ \\
\hline & $60 \mathrm{~s}$ & 64.30 & $57.96-70.63$ & $<0.01$ \\
\hline \multirow{5}{*}{ Transversus abdominis } & $20 s$ & 19.42 & $13.08-25.75$ & \\
\hline & $30 s$ & 32.90 & $25.74-40.05$ & $<0.01$ \\
\hline & $40 \mathrm{~s}$ & 34.07 & $27.60-40.55$ & $<0.01$ \\
\hline & $50 \mathrm{~s}$ & 48.68 & $42.72-54.64$ & $<0.01$ \\
\hline & $60 \mathrm{~s}$ & 46.00 & $39.67-52.33$ & $<0.01$ \\
\hline \multirow{5}{*}{ Erector spinae } & $20 \mathrm{~s}$ & 36.14 & $29.81-42.47$ & \\
\hline & $30 \mathrm{~s}$ & 41.89 & $34.73-49.05$ & 0.238 \\
\hline & $40 \mathrm{~s}$ & 47.91 & $41.43-54.38$ & $<0.05$ \\
\hline & $50 \mathrm{~s}$ & 54.54 & $48.58-60.79$ & $<0.01$ \\
\hline & $60 \mathrm{~s}$ & 64.11 & $57.78-70.45$ & $<0.01$ \\
\hline \multirow{5}{*}{ Lumbar multifidus } & $20 \mathrm{~s}$ & 30.22 & $23.89-36.55$ & \\
\hline & $30 s$ & 34.23 & $27.07-41.39$ & 0.410 \\
\hline & $40 \mathrm{~s}$ & 41.06 & $34.58-47.53$ & $<0.05$ \\
\hline & $50 \mathrm{~s}$ & 49.52 & $43.56-55.48$ & $<0.01$ \\
\hline & $60 s$ & 51.36 & $45.02-57.69$ & $<0.01$ \\
\hline
\end{tabular}

Foot note: the linear mixed effect models were performed by MT or EI of each muscle as dependent variables; subjects as random effects; and age groups, muscle parts, and confounding factors between age groups with muscle parts as fixed effects. Significant difference compared to the 20s age group are shown in bold. 